\title{
Numerical Study on the Stability of Railway Bridge Girder under Tsunami-Induced Loading
}

\author{
Chathura MANAWASEKARA ${ }^{1}$, Yukinobu ODA $^{2}$, Takahide HONDA ${ }^{3}$ and Ken \\ WATANABE 4
}

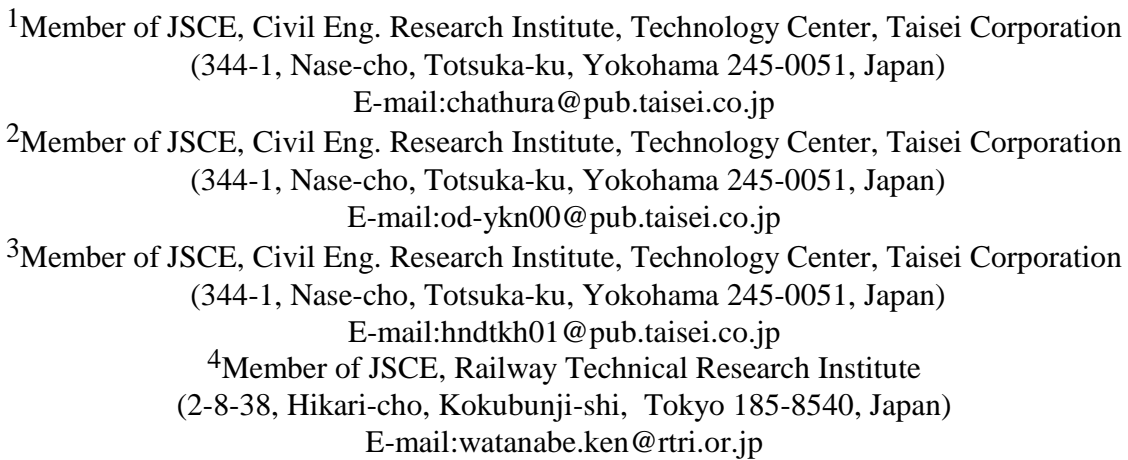

\begin{abstract}
Bridges are playing a vital role in the post-tsunami reconstruction process providing access to the damaged areas. Therefore, as it is costly to reconstruct the bridge itself, a damaged bridge is also a huge setback for the mobility of resources. In the current study, tsunami flow over three types of bridge sections was numerically simulated to assess the behaviour of tsunami-induced loading, and results are compared with the existing physical experiment results. Failure of bridge girder by the lateral movement was well reproduced in the three-dimensional numerical simulation. The temporal variation of the reaction forces at the girder bearings was also agreed well with the physical experiment results and discussed in the paper.
\end{abstract}

Key Words : tsunami, fluid force, coastal bridges, uniform flow

\section{INTRODUCTION}

Transportation structures are playing a vital role in the post-tsunami reconstruction process providing access to the damaged areas. Therefore, in addition to the costly reconstruction work, a damaged bridge is also a crucial setback for the mobility of resources including relief supplies, and post-tsunami recovery. In a country like Japan, which is facing tsunami threats in relatively regular basis, still has a majority of important railway and highway transportation lines lying through tsunami prone Pacific coastal areas. The vast variety of damages to the coastal transportation infrastructures including coastal bridges, which observed in the recent past tsunami events ${ }^{1)}$ have highlighted the vulnerability and the inadequacy in load bearing capacity of the existing coastal bridge structures against the tsunami. In contrast to enhancing the load bearing capacity, as an alternative design approach, superstructure can also allow being washed out by limiting the bearing ca- pacity which will reduce the load on the substructure of the bridge. Either way, to apply necessary modifications and to implement tsunami-resilient countermeasures into the bridge design, it is essential to have a proper understanding of the behavior of tsunami-induced loading on a bridge structure.

At the same time, having able to numerically reproduce such physical scenarios can broaden the understanding of engineering aspects. In parallel to the development of numerical computation capabilities, in the recent decades, fluid-structure interaction simulation has gained a significant uplift, allowing the analysis of complex situations such as tsunami-structure interactions. Which is immensely helpful in effective analyzing of the tsunami interaction with structures consist of rather complicated geometrical shapes.

In the current study, three-dimensional numerical simulation and analysis were conducted for three types of bridge sections (shapes are which commonly used in transportation bridge structures) with rela- 


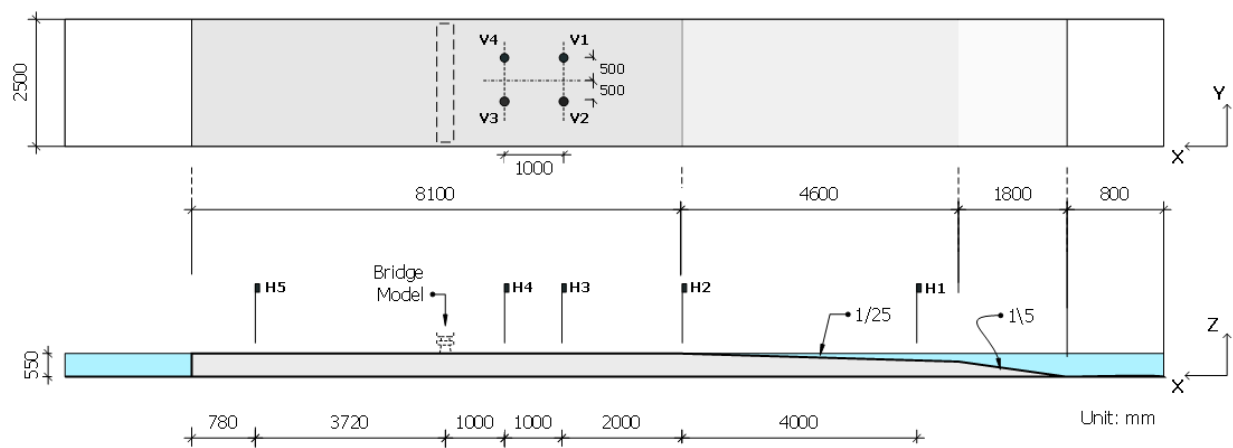

Fig.1 Experiment Set-up; Aerial view (top) and elevation view (bottom)

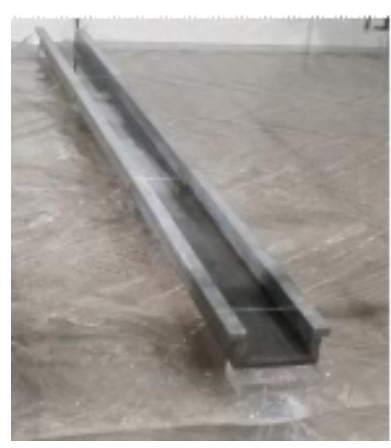

Fig.2 Physical bridge model with G1 section tively large beam depth, and results are compared with the existing physical experiment results.

\section{EXPERIMENT STUDY}

Physical model experiments (1:40 Froude scale) were conducted in a $2.5 \mathrm{~m}$ width channel section created in the wave basin of Taisei Corporation. The arrangement of the experimental set-up is depicted in Fig. 1. Tsunami flow was simulated with a uniform flow through the channel. Inflow to the channel section was controlled using hydraulic pumps, and the flow discharge was gradually increased as the experiment progress. Three types of bridge girder sections (G1, G2, and G3) cast with fiber concrete were employed (Fig. 3), and were mounted on $125 \mathrm{~mm}$ high rigid pier modules which are fabricated out of acrylic glass. Bridge structure consisted with three spans (each span with $750 \mathrm{~mm}$ in length), and only the center span was allowed to move freely. At the initial position, center span girder was resting on the two center piers of the bridge with no contact with neighbouring girders, while rest of the structure was remained fixed in the space. Fig. 2 shows the bridge

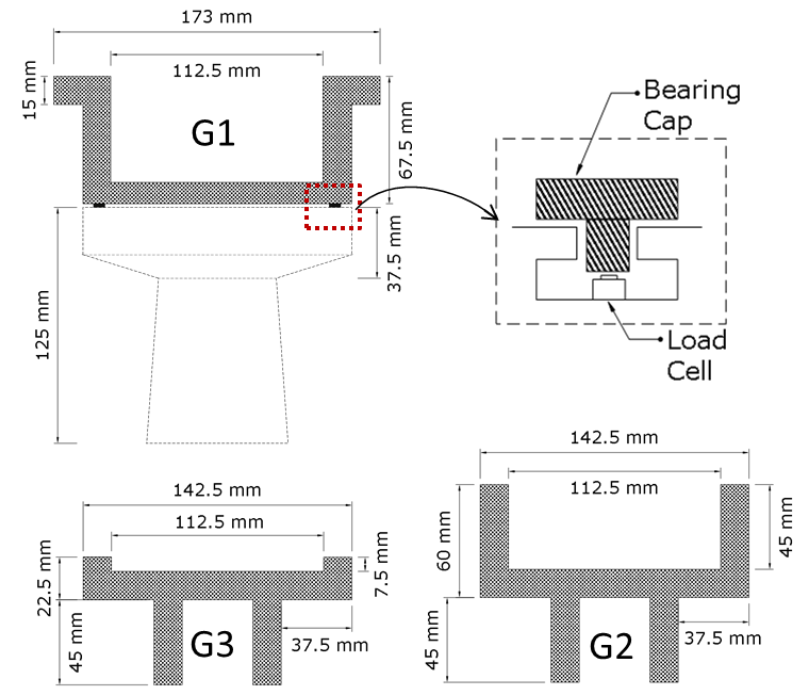

Fig. 3 Bridge girder sections used in the experiment and set-up of the bearing module model with G1 section during the experiment. Bearing modules were applied at the contact interface of the bridge girder and pier, each of which consisted with a load cell to measure the vertical reaction force acting on the girder (Fig. 3). The top surface of the bearing cap was $0.01 \mathrm{~m} \times 0.01 \mathrm{~m}$ in area, and was made out of rubber material. Moreover, in order to obtain the flow parameters, five wave gauges (H1-H5) and four velocity gauges (V1-V4) were installed at the locations indicated in Fig. 1. Here, V2 and V4 were located at a fixed position elevated $60 \mathrm{~mm}$ above the bottom bed, while locations of V1 and V3 were shifted from 110 to $170 \mathrm{~mm}$ above the bed as incoming flow depth increases during the experiment. Data sampling of the gauges was conducted at a rate of $10 \mathrm{~Hz}$. The experiment was continued while gradually increasing the flow discharge (around 500s for a single case) until the girder is dislodged from the pier. A detailed description of the experiment set-up is available in Watanabe et al. $^{2)}$.

\section{NUMERICAL STUDY}

The numerical simulation study was conducted with the aim of investigating there-producibility of the physical mechanism of fluid interaction with the bridge structure including the washout of the super-structure, and closely observe the flow mechanism around the girder and its influence on the failure. A three-dimensional numerical model which is capable of analyzing air-fluid-structure interaction was adopted for the study.

\section{(1) Outline of the numerical model}

The three-dimensional two-way coupled fluid-structure-sediment interaction model by Nakamura and Mizutani ${ }^{3)}$ was adopted for the current study. The main solver is a Large Eddy Simulation (LES) model based on continuity and momentum equations for incompressible viscous air-water flow. 


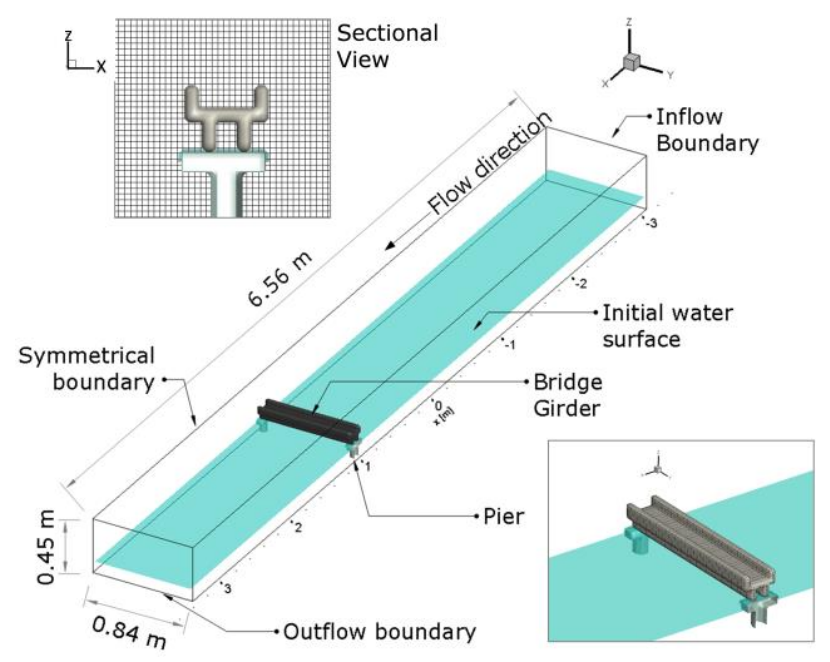

Fig. 4 Arrangement of the computational domain

Two out of three modules incorporated in the model was used in this particular study to simulate the tsunami-bridge interaction. First one is a volume of fluid (VOF) module based on the multi-interface advection and reconstruction solver (MARS) ${ }^{4)}$ for air-water interface tracking. The second one is an immersed boundary (IB) module based on the volume-force type of IB method ${ }^{5)}$ for the motion of the movable structure.

When the VOF method is concerned, VOF function $F(0 \leq F \leq 1)$ represents the fraction of the fluid volume in each cell. Where $F=0$ for pure air and $F=1$ for pure water while $0<F<1$ at the air-water interface. A similar concept is adopted in the volume force type of IB method with the volume fraction of the structure in the each cell $F_{\mathrm{ob}}\left(0 \leq F_{\mathrm{ob}} \leq 1\right)$. Where, $F_{\mathrm{ob}}=0$ for outside the structure, $F_{\mathrm{ob}}=1$ for the structure while $0<F_{\text {ob }}<1$ for the structure surface. Moreover, volume porosity $m(0 \leq m \leq 1)$ represents the volume fraction of void in each cell, as $m=0$ for the pure solids and $m=1$ for the pure fluids while $0<m<1$ for the porous media.

The extended governing equations for continuity, momentum and fluid-air interface motion are respectively described as,

$$
\begin{gathered}
\frac{\partial\left(m v_{j}\right)}{\partial x_{j}}=q^{*} \\
\left\{m+C_{A}(1-m)\right\} \frac{\partial v_{i}}{\partial t}+\frac{\partial\left(m v_{i} v_{j}\right)}{\partial x_{j}} \\
=-\frac{m}{\hat{\rho}} \frac{\partial p}{\partial x_{i}}+m g_{i}+\frac{m}{\hat{\rho}}\left(f_{i}^{s}+R_{i}+f_{i}^{o b}\right) \\
+\frac{1}{\hat{\rho}} \frac{\partial}{\partial x_{j}}\left(2 m \hat{\mu} D_{i j}\right)+\frac{\partial\left(-m \tau_{i j}^{a}\right)}{\partial x_{j}}+Q_{i}+m \beta_{i} \\
m \frac{\partial F}{\partial t}+\frac{\partial\left(m v_{j} F\right)}{\partial x_{j}}=F q^{*}
\end{gathered}
$$

Where, $p$ is pressure; $x$ is position vector; $t$ is time; $g$ is gravitational acceleration; $\hat{\rho}$ is density of fluid $\left[\hat{\rho}=F \rho_{w}+(1-F) \rho_{a}\right] ; \rho_{w}, \rho_{a}$ are density of water and air respectively; $\hat{\mu}$ is molecular viscosity of fluid, $C_{A}$ is added mass coefficient; $R$ is laminar and turbulent force vector due to porous media; $f^{s}$ is surface tension force vector; $\tau_{i j}$ is turbulent stress tensor; $D_{i j}=\partial v_{i} / \partial x_{j}+\partial v_{j} / \partial x_{i}$ is strain rate tensor; $q^{*}$ is intensity of wave generation source/sink per unit of time; $Q_{i}$ is wave generation source/sink vector; $\beta_{i}$ is artificial damping factor vector; $a$ is anisotropic part of a tensor. A detailed description of the model is available in Nakamura and Mizutani ${ }^{3)}$.

\section{(2) Arrangement of computational domain}

The simulation was conducted similar to the experiment scale, but only considering a single span $(0.75 \mathrm{~m}$ in length) of the bridge, and hence the size of the numerical domain and the inflow rate was selected accordingly. The domain size was $6.56 \mathrm{~m} x$ $0.84 \mathrm{~m} \times 0.45 \mathrm{~m}$ for all the cases, and only the region with the horizontal bed surface was included in the simulation. Minimum mesh sizes around the bridge in each direction, $\Delta \mathrm{x}, \Delta \mathrm{y}$ and $\Delta \mathrm{z}$ were applied as $0.01 \mathrm{~m} \times 0.01 \mathrm{~m} \times 0.01 \mathrm{~m}$. The size of the mesh in $\mathrm{x}$-direction was varied between $0.01 \mathrm{~m} \sim 0.025 \mathrm{~m}$ when moving away from the bridge, to save the computational cost. Additionally, to further reduce the computational cost due to the relatively long experiment time, the numerical simulation was limited to a maximum of a $72 \mathrm{~s}$ period for each case. Simulation started at the non-submerge condition of the girder with initial water surface $0.025 \mathrm{~m}$ below the girder bottom level. The basic set-up of the numerical domain together with boundary conditions is illustrated in the Fig. 4. Here, half of the supporting rigid pier sections were included in each side of the girder, while the girder was resting freely on the piers with provision to translate and rotate. The friction force was acting on the girder bottom as a resistance to the lateral movement, at the contact surface with the pier, in the direction opposite to the direction of

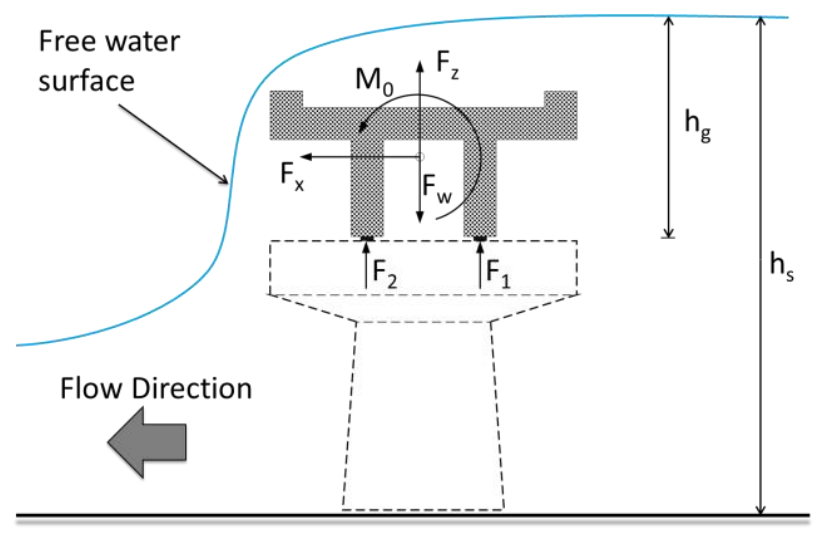

Fig 5 Acting forces on the girder 

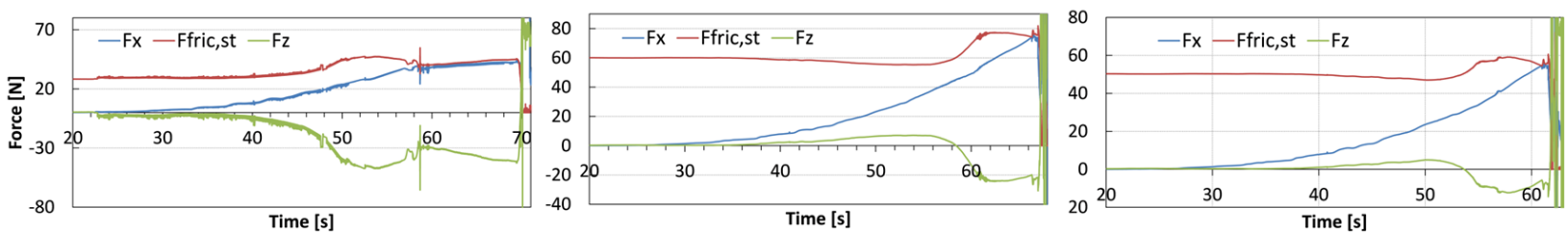

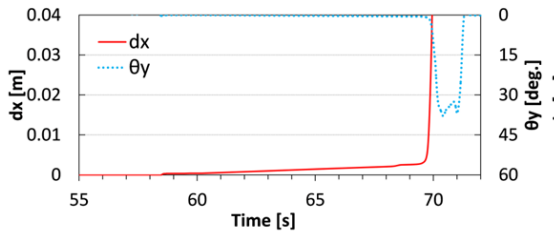

(a) G1

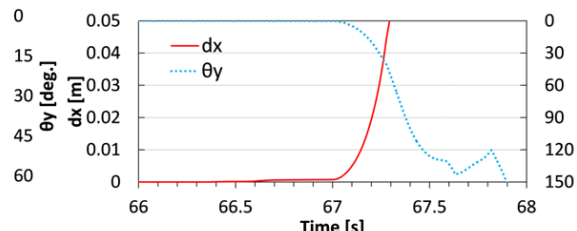

(b) G2

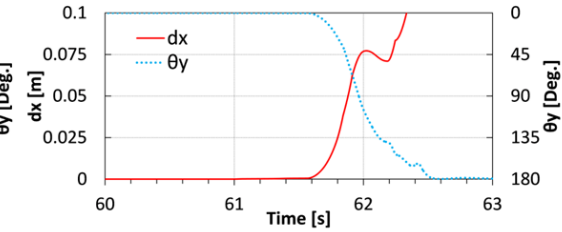

(c) G3

Fig. 6 Fluid forces (horizontal-Fx; vertical-Fy) and static friction force $\left(\mathrm{F}_{\text {fric,st }}\right)$ on the each girder, and their horizontal displacement $(\mathrm{dx})$ and rotation around $\mathrm{y}$-axis $(\theta y)$ at the washout (numerical simulation).

movement. The coefficient of friction, $\mu$, at the bearings was allocated considering rubber-concrete interaction surface. $\mu=0.4$ was used for the G1 section while $\mu=0.7$ for $\mathrm{G} 2$ and $\mathrm{G} 3$ sections. The weight of the bridge girders was assigned similar to the physical experiment values as, $7.256 \mathrm{kgf}, 8.779 \mathrm{kgf}$ and $7.359 \mathrm{kgf}$ for $\mathrm{G} 1, \mathrm{G} 2$ and $\mathrm{G} 3$ respectively.

\section{RESULT AND DISCUSSION}

\section{(1) Fluid force on the girder}

Fluid forces acting on the girder in horizontal and vertical directions ( $F_{\mathrm{x}}$ and $F_{\mathrm{z}}$ respectively), and the moment around y-axis $\left(\mathrm{M}_{0}\right)$ were estimated during the simulation (Fig. 5). The temporal variation of $F_{\mathrm{x}}$, $F_{\mathrm{y}}$ and static friction force $\left(F_{\text {fric,st }}\right)$ for each case are shown in Fig. 6. Here $F_{\mathrm{x}}$ is considered to be positive in the x-direction and for $F_{\mathrm{z}}$ is in the upward direction.

According to the figure, generally, for all the cases $F_{\mathrm{x}}$ gradually increases with time following the contact with the flow and with the rise of the upstream flow depth $\left(h_{\mathrm{s}}\right) . F_{\mathrm{x}}$ reaches its maximum value just prior to the washout. The time that girder completely dislodged from the piers $\left(t_{\mathrm{c}}\right)$ for G1, G2 and G3 are $69.7 \mathrm{~s}, 67.1 \mathrm{~s}$ and $61.7 \mathrm{~s}$, respectively. It is evident from the figure that, at this critical time $\left(t=t_{\mathrm{c}}\right)$, the

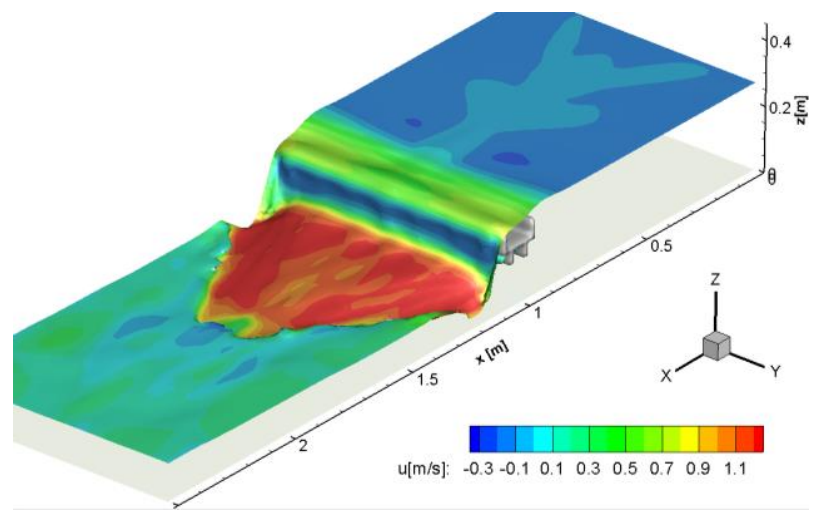

Fig. 7 Surface flow velocity in $\mathrm{x}$-direction over G2 girder at $66.8 \mathrm{~s}$ static friction force acting on the girder is equivalent to the $F_{\mathrm{x}}\left(F_{\mathrm{x}}=F_{\text {fric,st }}\right)$, which counterbalance the horizontal force and prevent the lateral movement. Here, friction force can be estimated as,

$$
F_{\text {fric,st }}=\mu\left(F_{W}-F_{Z}\right)
$$

where, $F_{\mathrm{w}}$ is the weight of the girder. With the slight increment in $F_{\mathrm{x}}$ exceeds the frictional resistance and initiate the washout of the girder. It can be seen from the displacement time history that lateral movement initiates the washout of the girders. Therefore, an increase of the friction force at the bearings will improve the stability and delay the failure of the girder. According to the Eq. (4) an increment in $F_{\text {fric,st }}$ can be achieved by three possible

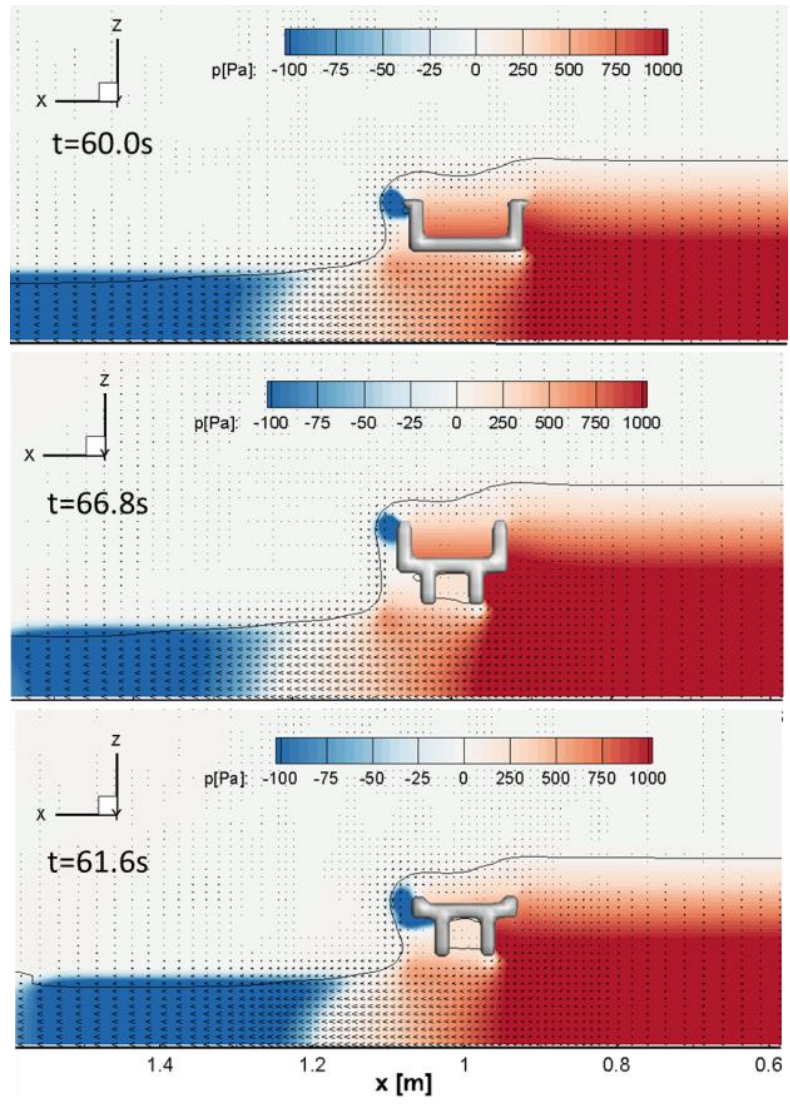

Fig.8 Fluid pressure distribution in $\mathrm{x}-\mathrm{z}$ section, around $\mathrm{G} 1, \mathrm{G} 2$ and $\mathrm{G} 3$ at $60 \mathrm{~s}, 66.8 \mathrm{~s}$ and $61.6 \mathrm{~s}$ respectively. 

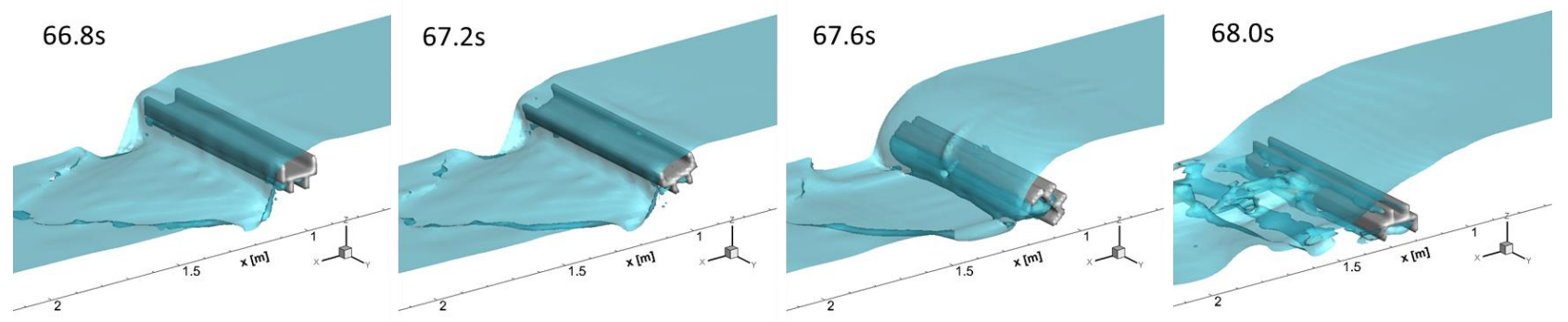

Fig. 9 Washout of G2 girder in the numerical simulation

scenarios; by increasing the friction coefficient $\mu$, by increasing the weight of the girder $F_{\mathrm{w}}$, or by reducing the lift force $F_{\mathrm{z}}$ during the interaction. An increase of the girder weight can lead to the increase of construction material which is generally limited by substructure stability requirements and cost restrictions. Therefore, for a given bearing condition, the variation of lift force has a significant influence on the limiting conditions of the washout.

It is visible from the Fig. 6 that flow overtopping of the bridge cause a significant increment in $F_{\text {fric,st }}$. For the girders G1, G2 and G3 overtopping started approximately at $45 \mathrm{~s}, 57 \mathrm{~s}$ and $52 \mathrm{~s}$, and fully-overtop the girder at 51s, 62s and 56s, respectively. This increment in $F_{\text {fric,st }}$ is mainly influenced by the additional weight of the water volume which added to the downward $F_{\mathrm{w}}$ of the girder, with the overflow. At the same time, the low-pressure regions caused due to the high velocity flow under the girder also can add an additional downward force on the girder. Flow surface velocity profile of the fully overtopped girder G2 (at $t=66.8 \mathrm{~s}$ ) is shown in Fig. 7, and the pressure variation around the girder in $\mathrm{x}-\mathrm{z}$ section under overflow condition for all the girders are depicted in Fig. 8. As seen in the figure, negative and low pressure zones are developed on the leeward side and in the bottom of the girder during the overflow. The extension of these low pressure zones also depends on the geometry of the section. Collectively, the initial friction force is increased (maximum) by $67 \%$, $28 \%$ and $17 \%$ for G1, G2 and G3 sections respectively in the simulation, during the overflow of the bridge. At the same time, the deck geometry of the G1 and G2 sections have relatively large water-retainable volume compare to $\mathrm{G} 3$, in which the retained mass of water has an effect on the variation

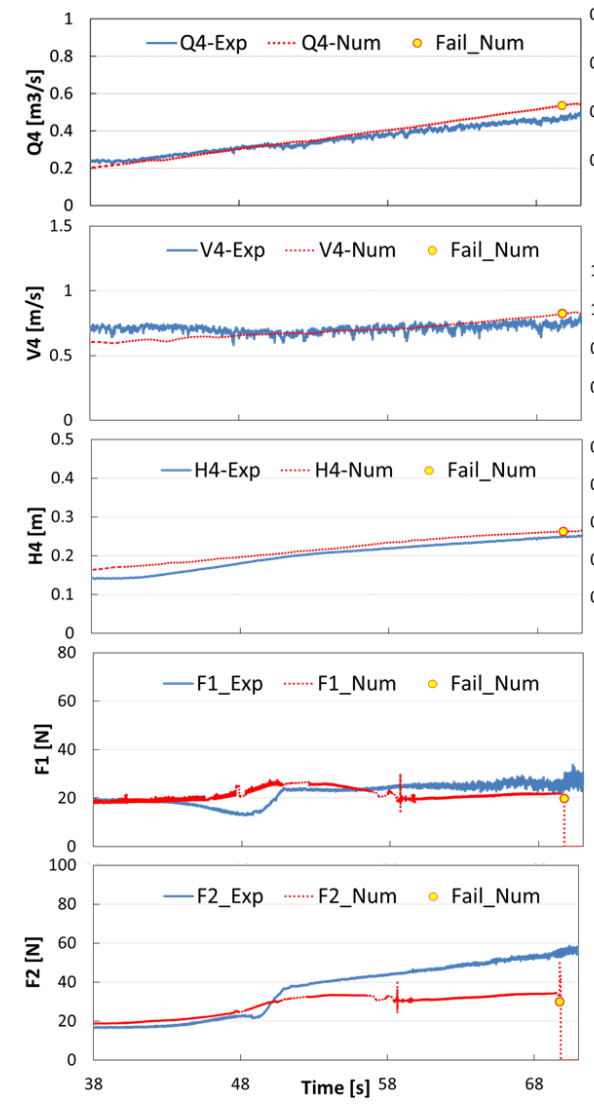

(a) G1

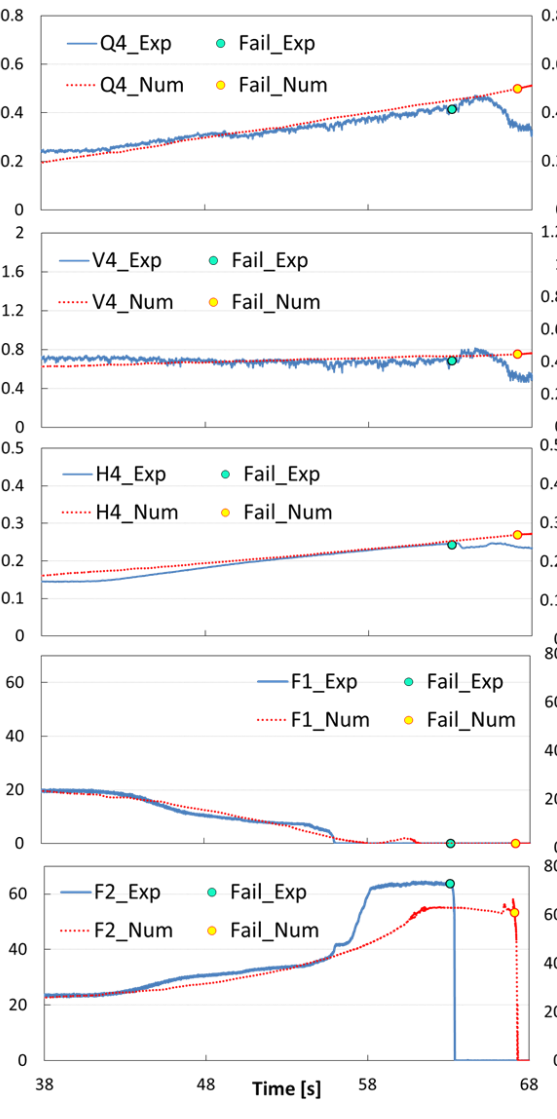

(b) G2

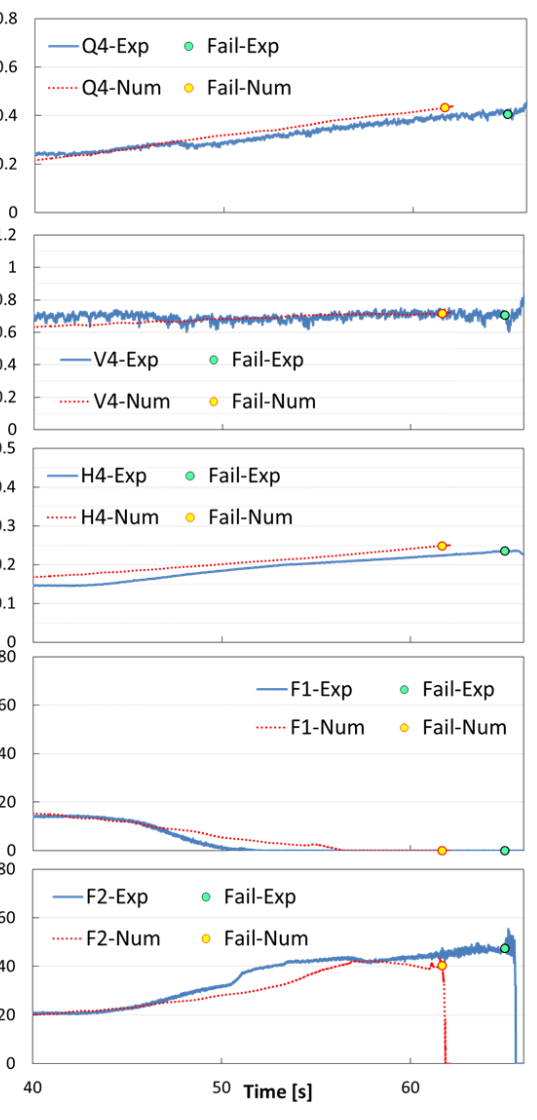

(c) G3

Fig. 10 Comparison of numerical and experiment results for each girder section 
in $F_{\text {fric,st }}$. According to the results, G1 section has appeared as the most effective section under overtopping conditions. Also, the washout of the G2 girder is depicted in Fig. 9, in consecutive time steps.

\section{(2) Comparison with experiment results}

As mentioned in the previous section, due to the simulation time limitation, the rate of change in the incoming discharge was different from that of the experiment, and therefore, experiment time value was scaled down by dividing with a factor $\beta$, to correspond with the simulation time value. The value of $\beta$ was obtained from, $\dot{Q}_{N u m}=(1 / \beta) \dot{Q}_{E x p}$ where, $\dot{Q}_{N u m}$ and $\dot{Q}_{\text {Exp }}$ are the rate of change of the inflow discharge for simulation and experiment, respectively. Since the rate of change in discharge were constants for both numerical simulation and experiment, $\beta$ was estimated as $\beta=7.367$ for the current study.

The temporal variation of the reaction forces $\mathrm{F} 1$ and F2 (Fig. 5) for each girder estimated from the numerical simulation were compared with that of physical experiment and shown in Fig. 10. Additionally, the numerical results of the flow depth at $\mathrm{H} 4$ gauge, flow velocity, V4, and flow discharge at the section, Q4, during the same time periods, are also compared with the experiment results. As visible from the figure, numerical results agree notably well with the physical experiment results. Even though there is a slight discrepancy in the variation of the F2 values of $\mathrm{G} 1$ and $\mathrm{G} 2$, the general behaviour of the reaction forces shows the similar pattern as of the experiment. Considering the bearing cap arrangement (Fig. 3; Right-up) in the experiment, a small rotation of the cap during the overflow conditions can cause a slight increase in vertical force on the load cell, which might make the F2 value of the experiment slightly higher than the numerical results. Additionally, a slight movement of G1, which starts around 59s and some mass of water leaked through the small gap at the either side of the girder during the simulation also might have contributed to these discrepancies. At the same time, values of the reaction forces at the time of the dislodge of $\mathrm{G} 2$ and $\mathrm{G} 3$ also shows a close agreement with the experiment results. Moreover, it can be noticed that the reaction force F1 for both G2 and G3 become zero (lose the contact with substructure) for a significant period prior to the washout, which is an indication that the resulting vertical force is acting fairly close to the leeward support of the girder. Thus the lateral movement of the girder is immediately followed by the rotation around the y-axis (Fig.6). Therefore, the leeward side support of the beam-girder type structure should be designed accordingly to bear with this additional load transferred under limiting conditions.

\section{SUMMARY AND CONCLUSIONS}

A three-dimensional numerical study was conducted considering the washout of a bridge girder under tsunami overflow. Results were also compared with the existing experiment results.

Numerical results showed a good agreement with the experiment results in the comparison of variation in flow conditions and the reactions at the bearing supports of the girder. The simulation also reproduced the flow conditions at the washout of the $\mathrm{G} 2$ and $\mathrm{G} 3$ girders with a notable accuracy.

A significant change in the acting static friction force was observed for all section types following the flow overtopping of the girder, which initial static friction force was increased by $67 \%, 28 \%$ and $17 \%$ for $\mathrm{G} 1, \mathrm{G} 2$ and $\mathrm{G} 3$, respectively.

G1 section with comparatively low elevated deck, wider supports and larger water retaining volume, showed a steady resilient compared to G2 and G3. The study will be continued further in an aim of developing countermeasures to enhance the resilience of bridge girders against tsunami overflow.

ACKNOWLEDGMENT: Authors would like to pay sincere gratitude to Prof. Norimi Mizutani and Assoc. Prof. Tomoaki Nakamura of Nagoya University for their valuable contribution to the research.

\section{REFERENCES}

1) Kawashima, K., Kosa, K., Takahashi, Y., Akiyama, M., Nishioka, T., Watanabe, G., Koga, H. and Matsuzaki, H.: Damage of bridges during 2011 Great East Japan Earthquake, Proc. of $43^{\text {rd }}$ Joint Meeting, US-Japan Panel on Wind and Seismic Effects, UJNR Tsukuba Science City, Japan, 2012.

2) Watanabe, K., Ohno, Y. and Oda, Y.: Experimental study on limit values for collapse of PC girders by uniformed flow of water, Proc. of Coastal Engineering, JSCE, Vol. 71, No. 2, I_1189-I_1194, 2015 (in Japanese).

3) Nakamura, T. and Mizutani, N.: Numerical simulation of local scouring around inland structure due to run-up tsunami using three-dimensional coupled fluid-structure-sediment interaction model, Proc. of $24^{\text {th }}$ CFD Symposium, JSFM, E10-4, 9 p., 2010 (in Japanese).

4) Kunugi, T.: MARS for multiphase calculation, CFD J., No.9, Vol. 1, IX-563, 1-10, 2000.

5) Kajishima, T., Takiguchi, S., Hamasaki, H. and Miyake, Y.: Turbulent structure of particle-laden flow in a vertical plane channel due to vortex shedding, JSME Int. J. Ser. B, Fluids and Thermal Eng., Vol. 44, No. 4, pp. 526-535, 2001.

(Received March 16, 2016) 